\title{
Ranking the methods of Technology cross-border acquisition, combining TOPSIS and ANP approaches for model development (case study of car part industry in Iran)
}

\author{
Somayeh Sahebi \\ Department of Industrial Management \\ Islamic Azad University, Tehran, Iran \\ E-mail: s.sahebi-in-management@yahoo.com \\ Arash Radmehr \\ Department of Industrial Management \\ Islamic Azad University, Tehran, Iran \\ E-mail: radmehr.contact@.gmail.com \\ Zeinab sahebi \\ Department of Industrial Management \\ Ershad-Damavand Higher Education Institute \\ z.sahebi.in.management@yahoo.com
}

\begin{abstract}
Simultaneous with the industries increasing growth, the companies must acquire the new technologies to achieve to core competency, survival and improvement and also effectiveness in market. Choosing the suitable acquisition mode of required technology is one of the critical strategic decisions in the field of technology management. Due to the importance of technology acquisition, the main objective of this study is to select an appropriate method of technology acquisition in car part industry by multi-dimensional factors of environmental, technological, capability and market. Hence, after extracting the factors from surveying the related literature and conforming the firs kind of questionnaire by the chorenbakh alpha's, the elements was ranked by TOPSIS method to reduce the criteria and to choose the appropriate affecting elements in technology acquisition modes. In the next step regarding to ANP method second questioners spread between the experts in the car part industry in Iran and the modes were prioritized and the applied recommendations have been suggested.
\end{abstract}

Keywords: technology acquisition modes, multi criteria decision making (MCDM), ranking, Combining the TOPSIS and ANP, Car part industry. 


\section{Introduction}

In according drastic changes in technology, developing countries are facing a serious struggle, so that most of these countries are seeking to acquire new technologies and are aware of their ability to leverage this technology to build modern industries (industries, countries and reducing the gap between industry findings) and consequently entering global markets has a significant impact. It is clear that developing countries have the technology needed for industrialization. Although the Burgers and colleagues (2008) continuing rapid change and acquisition of new developments that provide technical knowledge to achieve innovation in the organization are continually required. Lanctat and Swan (2000) show the company's ability to develop and exploit the technology knowledge of basic dimension competition is expressed in many industries.

Thus, according to Hyun Dai This is the best reason for why strategic decisions, technology management to study the internal conditions to enable it to quickly adapt themselves to changing environments' requires. On the other hand, it is an undeniable truth that there should be applied both domestic and new technology to ease the tough sanctions opposite Iran. Several studies have classified technology acquisition methods and the progress that industry has the highest priority factors that must be considered. In according existence conditions these subjects is surveyed in the car part industry in Iran to achieve key factors in car part industry and model development for decision making.

\section{Literature Review}

Technology can be machines, products or services embodied. This information can be accumulated experiences in $\mathrm{R} \& \mathrm{D}$, design, production and investment is arising. According to the process of technology transfer, Nelson and winter (1982) and Fine (1992) concluded that the most important feature of technology transfer process model, social and technical, interaction of innovation acquisition and supplier is that outlines the key factors of learning and the development. Learning and development involve Individual learning and organizational. Using innovative technology transfer so that organizations must continuously adapt to changes likely to be associated, is emphasized. To create new technology, new organizational practices and indigenous knowledge and tacit knowledge is required. On the other hand, Gregory (1995) five-stage model for the management of their technology, the acquisition and localization technology has emphasized. These steps are:

1. Identify technologies that are considered important for business

2. To choose technologies that should be provided by the organization

3. Acquisition and implementation of selected technologies

4. Exploitation of technologies that is beneficial

5. Protection of the experts' knowledge used in the manufacture of products and systems

Gregory's model is related to other models such as the Model Sumanth (1996), which includes consciousness and assimilation, adaptation, development and progress and assignment. Therefore, in developing countries to reduce the gap between developed and developing countries as well as technology development, transfer and acquisition of technology management to appropriately address the technology used.

In according the literature review factors below were extracted.

1. Intent to learn

2. Active assistance of foreign acquiring firms in technology management

3. Appropriability regime

4. R\&D experience

5. R\&D activity

6. Technology level

7. Business risk (uncertainty)

8. Market size

9. Ease of imitate 
10. Technical position

11. Availability of external sources

12. Gov. Support for R\&D cooperation

13. Developing cost

\section{Hypotheses/Objectives}

the research objectives:

The main objective of the research :

- Choosing the appropriate method to acquire the requisite technology using the influential factors.

Secondary research objective :

- determining the effective factors of technology acquisition mode in IRAN's car part industry.

\section{Research Design/Methodology :}

According to Kondo (2001) as one of the essential concepts of technology strategy, technology acquisition modes should be carefully selected. According to Lee and Park (2008), i.e., the selection of a suitable required acquisition technology method is a critical strategic decision to implement a technology strategy. Also, Cho and yu (2000) suggests these criteria may be due to the comparison between different industries, across countries, the differences between SMEs and large firms provide somewhat different results.

The data collection for this study was descriptive research because it involves a series of procedures that aim to explain the position of the phenomena of the investigation. This research is based on the objective of the applied research. Applied research will lead to practical application of knowledge. Using TOPSIS 13 factors reduced to 6 the. . Since this research investigates the factors affecting in technology acquisition modes, it is descriptive survey study. Results of this research facilitate decision-making (ANP). So decision-making techniques (ANP and TOPSIS) and its application were discussed based on two kinds of questioners.

The diagram below shows the stages of the methodology.

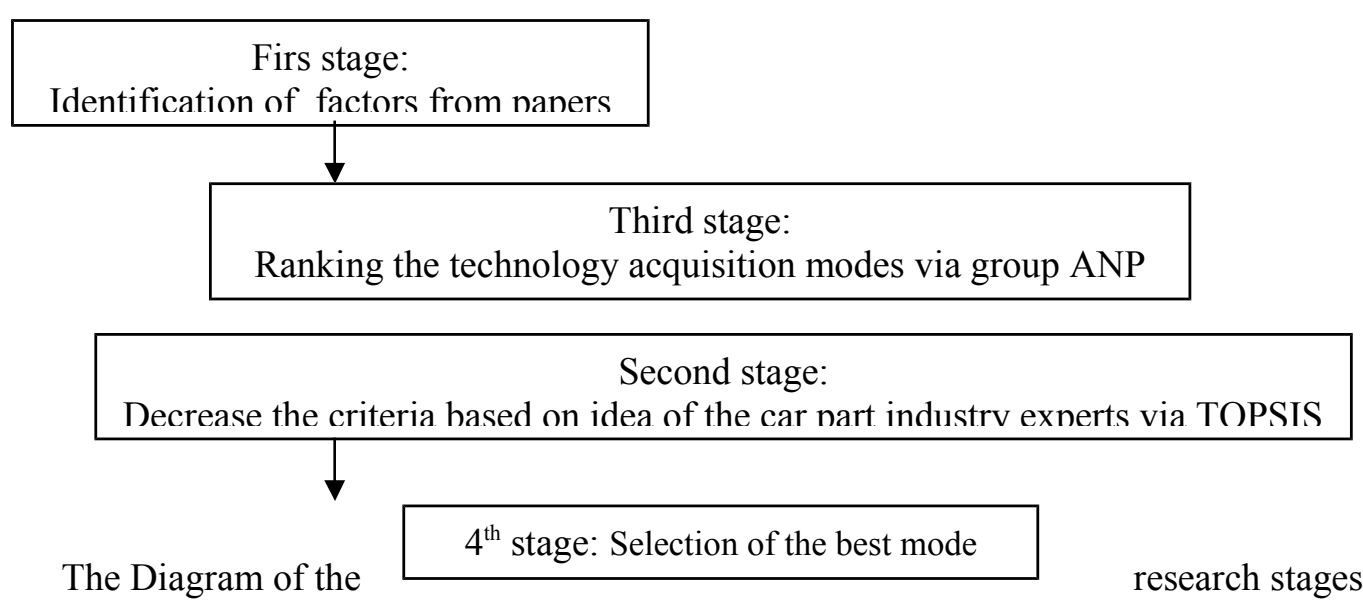

\section{Data/Model Analysis}




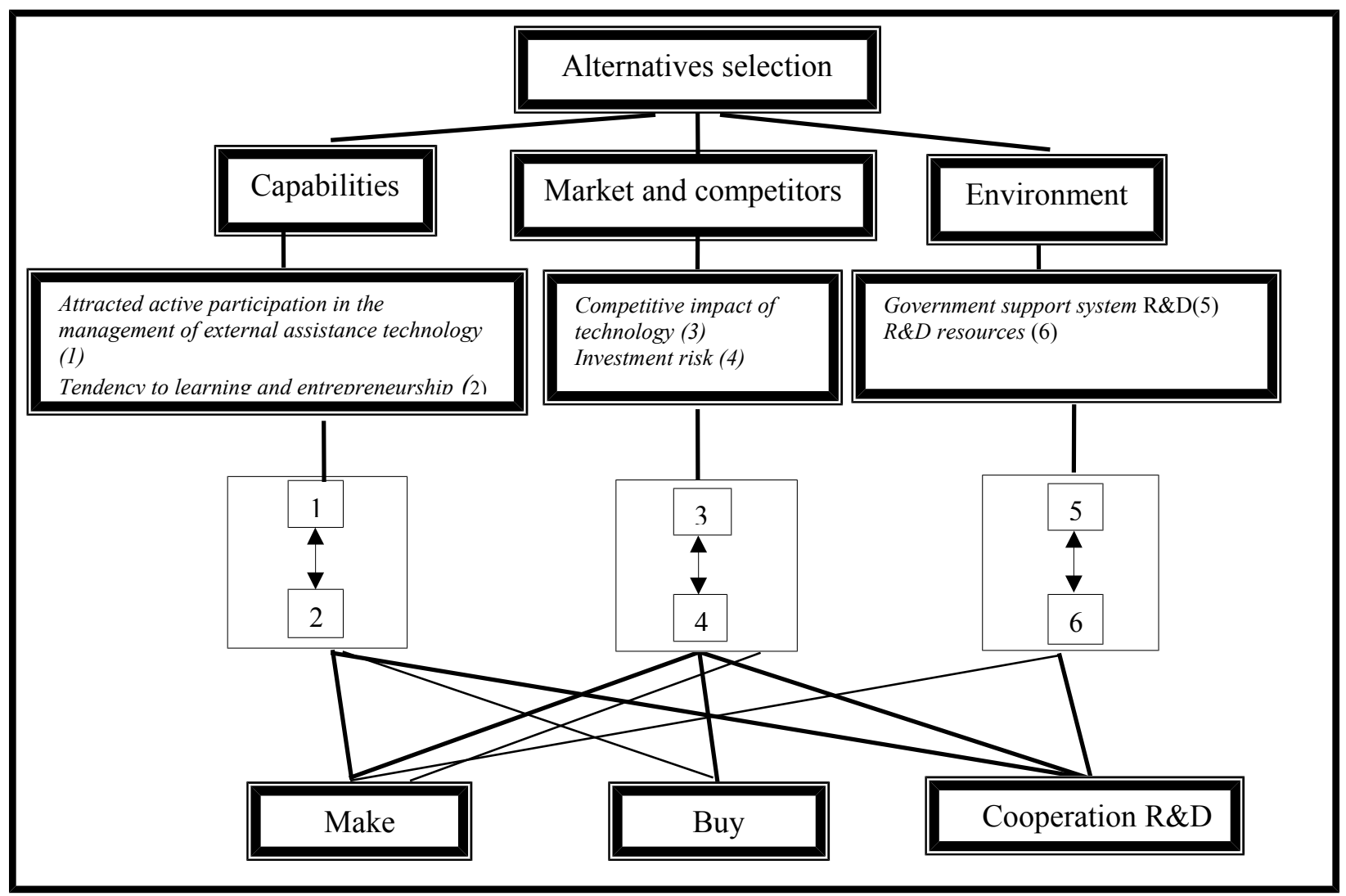

\section{Limitations}

There are some limitations including:

1. Time limitation and massive required information

2. Lack of experts in related industry

\section{Conclusions}

Despite all the challenges, technology acquisition is the inevitable alternative in developing countries to achieve sustainable economic growth and development. Naturally this route chooses appropriate strategies at the national, creating the necessary legal infrastructure and selection of the efficient methods to receive technologies to reduce the gap between developed and developing countries, is an important issue. To develop techniques Based on the selected model, the first step of the proper institutional acquisitions way is acquisition requirements analysis. $\mathrm{R} \& \mathrm{D}$ with a weight of 0.39 in the first rank, build and buy options with 0.33 and 0.27 are in order in the second and third priorities. Sensitivity analysis can be used to identify and suggest that the increase or decrease in the dependent variables and one independent variable (technology acquisition methods) how will the change. Thus it can be predicted to change the options on the industry, what factors should be improved. On the other hand, due to existence situation, in house $R \& D$ can create a huge change in car part industry in Iran. 
The weight of factors resulted from TOPSIS model: (selected factors have been highlighted. )

\begin{tabular}{|lc|c|c|c|c|r|c|c|c|c|c|c|c|}
\cline { 2 - 12 } \multicolumn{1}{c|}{} & $\mathbf{1}$ & $\mathbf{2}$ & $\mathbf{3}$ & $\mathbf{4}$ & $\mathbf{5}$ & $\mathbf{6}$ & $\mathbf{7}$ & $\mathbf{8}$ & $\mathbf{9}$ & $\mathbf{1 0}$ & $\mathbf{1 1}$ & $\mathbf{1 2}$ & $\mathbf{1 3}$ \\
\hline $\boldsymbol{E}_{j}$ & 0.367 & 0.37 & 0.37 & 0.366 & 0.367 & $\begin{array}{r}0.36 \\
2\end{array}$ & 0.37 & 0.366 & 0.37 & 0.369 & 0.366 & 0.369 & 0.369 \\
\hline $\boldsymbol{D}_{j}$ & 0.632 & 0.629 & 0.629 & 0.633 & 0.637 & $\begin{array}{r}0.62 \\
9\end{array}$ & 0.63 & 0.629 & 0.630 & 0.633 & 0.630 & 0.633 & 0.630 \\
\hline $\boldsymbol{W}_{j}$ & 0.077 & 0.076 & 0.076 & 0.077 & 0.077 & $\begin{array}{r}0.07 \\
6\end{array}$ & $\begin{array}{r}0.07 \\
7\end{array}$ & 0.076 & 0.076 & 0.077 & 0.076 & 0.077 & 0.076 \\
\hline
\end{tabular}

The table below was concluded from research:

The output of ANP software

\begin{tabular}{|c|c|l|l|l|c|}
\hline Graphic & Alternatives & Total & Normal & Ideal & Ranking \\
\hline & 1A-make & 0.165 & 0.33 & 0.83 & 2 \\
\hline & 2A-buy & 0.137 & 0.27 & 0.69 & 3 \\
\hline & 3A-R\&D & 0.197 & 0.39 & 1 & 1 \\
\hline
\end{tabular}

\section{Key References}

1. Lee, s .Lee h,park,y. (2009) Selection of technology acquisition mode using the analytic network Process, Mathematical and Computer Modelling 49.1274_1282

2. Saaty. T.L . ,(1996) Decision making with Dependence and feedback,RWS publications,Pittsburgh,PA.

3. saaty. T.L.(2004 B) the analytic network process :dependence and feedback in decision making(part1) theory and validation Examples, Canada : whistler,B.C.

4. Saaty. T.L.(1999A) Fundamental of the analytic network process.ISAHP japan:kobe.

5. Park, B. I. Ghauri, P. N. (2010) Key factors affecting acquisition of technological capabilities from foreign acquiring firms by small and medium sized local firms. Journal of World Business, doi:10.1016/j.jwb.2010.05.023

6. Velasquez Mark and Hester. T .Patrick.(2013) An Analysis of Multi-Criteria Decision Making Methods, International Journal of Operations Research Vol. 10, No. 2, 56-66. 